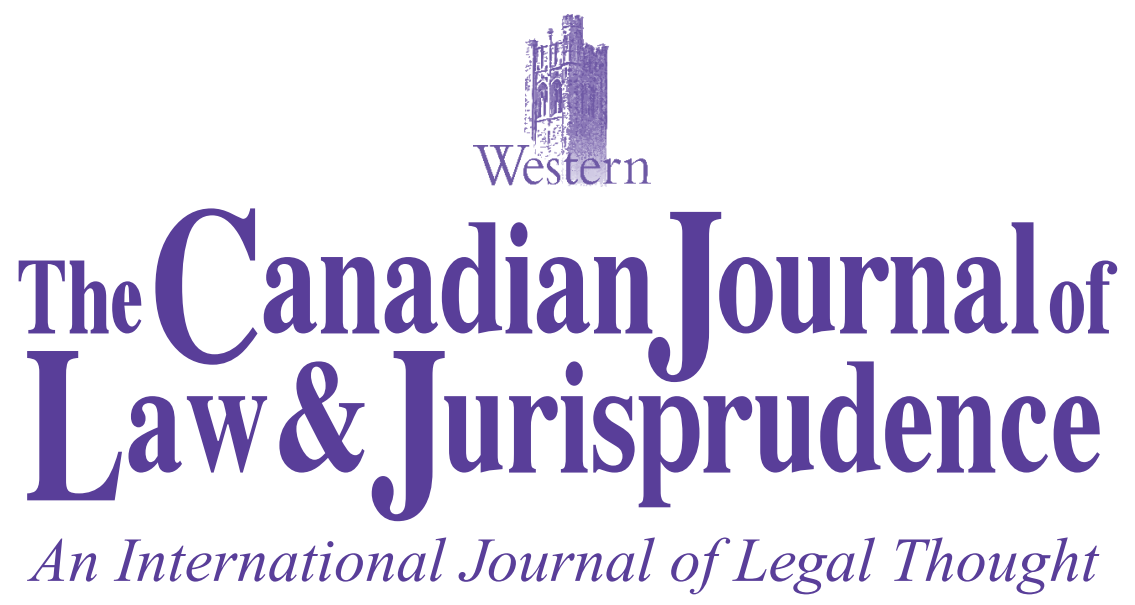

Editor: Richard Bronaugh

Jeremy Waldron

David Reidy

Allen Mendenhall

Ishani Maitra and Mary Kate McGowan

Geoffrey W.G. Leane

Ori J. Herstein

Douglas E. Edlin

Sean Coyle

Mátyás Bódig

Critical Notice

Andrew Halpin
The Coxford Lecture:

Inhuman and Degrading Treatment:

The Words Themselves

Human Rights and Liberal Toleration

Jefferson's "Laws of Nature": Newtonian Influence and the Dual Valence of Jurisprudence and Science

On Racist Hate Speech and the Scope of a

Free Speech Principle

Deliberative Democracy and the Internet:

New Possibilities for Legitimising Law through

Public Discourse?

Responsibility in Negligence:

Why the Duty of Care is not a Duty "To Try"

Kant and the Common Law:

Intersubjectivity in Aesthetic and Legal Judgment

The Intellectual Commitments of Modern

Juridical Thought

Legal Theory and Legal Doctrinal Scholarship

The Province of Jurisprudence Contested

The Province of Jurisprudence Democratized

by Allan Hutchinson 
The CANAdian Journal of LAW AND JURISPRUdENCE is published biannually. Appreciation is expressed to SSHRC for the aid to scholarly journals we receive. Articles may be sent by e-mail attachment, preferably in Word, to: CJLJeds@uwo.ca or by ordinary mail to The Editor, Canadian Journal of Law and Jurisprudence, Faculty of Law, UWO, London ON, Canada N6A 3K7. Authors are asked not to send their document "prepared for blind review" or in PDF. Footnotes should conform to the Canadian Guide to Uniform Legal Citation, 6th ed. Authors will receive 10 offprints (additional offprints are available at cost) and a free copy of the issue in which their article appears. Authors will hold the copyright in the text of their article while the Journal holds copyright in the format in which the article appears in the Journal and has the right of first publication and distribution of the article in that format.

Abstracts of articles are available at our Web Page:

http://www.law.uwo.ca/faculty_staff/cjlj.html

ANNUAL SUBSCRIPTION (two issues), including postage and handling: Individuals

$\$ 60.00 \mathrm{CAD}+$ tax in Canada

$\$ 66.30 \mathrm{CAD} / \mathrm{USD}$ to USA

$\$ 71.80 \mathrm{CAD} / \mathrm{USD}$ to Rest of World

Institutions

$$
\begin{aligned}
& \$ 104.60 \mathrm{CAD}+\text { tax in Canada } \\
& \$ 110.90 \mathrm{CAD} / \mathrm{USD} \text { to USA } \\
& \$ 116.40 \mathrm{CAD} / \mathrm{USD} \text { to Rest of World }
\end{aligned}
$$

Single copies from the current volume and four years prior cost half the annual subscription price. Back issues may be purchased, subject to availability, at a substantial discount off the regular price, plus postage $(\$ 8.10 /$ issue in Canada, $\$ 11.25$ /issue to USA, $\$ \mathbf{1 4 . 0 0 / i s s u e ~ t o ~ R e s t ~ o f ~ W o r l d ) . ~}$

Invoices are mailed annually with the January issue, but prepayment is also accepted. Cancellations must be received by December 31. Information concerning back issues and subscriptions, as well as new orders, may be secured from Tigger Jourard, Business Manager, CJLJ, Faculty of Law, UWO, London ON, Canada N6A 3K7. Phone: (519) 661-2111, ext. 88406. Fax: (519) 661-3790. E-mail: CJLJ@uwo.ca 


\title{
Responsibility in Negligence: Why the Duty of Care is not a Duty "To Try"
}

\author{
Ori J. Herstein
}

\section{Introduction}

Even though it offers a compelling account of the responsibility-component in the negligence standard - arguably the Holy Grail of negligence theory - it is a mistake to conceive of the duty of care in negligence as a duty to try to avert harm. My goal here is to explain why and to point to an alternative account of the responsibilitycomponent in negligence.

The flaws in conceiving of the duty of care as a duty to try are: failing to comport with the legal doctrine of negligence and failing as a revisionary account for the law; overly burdening autonomy and restricting the liberty of thought; adversely affecting the prevention of negligent harm - the essence of the negligence standard-; and, raising severe probative difficulties. Moreover, the duty of care also does not give rise to what I call a de facto duty to try.

The duty of care is better construed to require only certain conduct and not trying. Returning to the primary appeal and motivation for exploring the validity of equating the duty of care with a duty to try - searching for the responsibility-component in the negligence standard - I argue that the responsibility-component in negligence does not take the form of an obligation to try but rather has a conditional form, manifested in the conditions of applicability of the negligence standard. In other words, the negligence standard comprises a conduct-based as opposed to a combined action-/intent-based duty (such as a duty to try) as its duty of care, a duty that only applies to actors who possess the capacity to intentionally or knowingly comply with it, or, put differently, possess the capacity to try.

\section{The Dual Structure of the Negligence Standard}

Where care is owed the negligence standard allows imposing liability for the foreseeable harmful outcomes of one's negligent conduct. Conduct is negligent where one who is subject to a duty of care fails to meet its standard of conduct, which usually requires, at a minimum, conduct that is reasonable. When negligent conduct results in foreseeable harm, the negligence standard is violated and liability in negligence may follow. ${ }^{1}$ In comprising these two elements - harming and caring - the

For their comments on previous drafts I am grateful to Keren Azulay, Ittai Bar-Siman-tov, Marc O. DeGirolami, Michael C. Dorf, Yonatan Even, Robert A. Ferguson, Christen Furka, Kent Greenawalt, Miguel Herstein, Uri D. Leibowitz, Shaul Zioni and the referees for the Canadian Journal of Law and Jurisprudence.

1. Violating the negligence standard is a necessary yet not a sufficient condition for liability in negligence. Not all negligent harms give rise to liability, certainly not to legal liability. For a discussion see H.L.A. Hart, Punishment and Responsibility (New York: Oxford University Press, 1968) at 136-57. Moreover, there are defenses from negligence liability, including contributory negligence, 
negligence standard comprises a dual duty. This dual duty imposes a disjunctive norm, demanding that one not cause or bring about certain harms by one's negligence. The disjunctive nature of the negligence norm is reflected in the fact that avoiding violating the negligence standard is achieved either by (a) not causing the harm (regardless of whether one did or did not take care not to cause it) or (b) taking care (to the appropriate extent) to avert causing the harm (regardless of whether or not one in fact caused the harm). Where one who is subject to the negligence standard (via a duty) fails to meet both disjuncts comprising the negligence standard - harming through careless conduct — one violates the standard and liability may ensue.

\section{The Duty of Care as a Duty to Try: Gardner's Approach and its Appeal}

\section{A. The Duty to Try}

In contrasting negligence with strict liability John Gardner, the Chair of Jurisprudence at Oxford University, draws a distinction between two types of duties. ${ }^{2}$ The first is a duty to succeed, which is a duty to $\phi$ (i.e., to do/not do $\phi$ ). The second is a duty to try, which is a duty to take certain action or to take certain measures with the view of $\phi$ ing. The duty to succeed is satisfied only if one actually $\phi \mathrm{s}$, regardless of whether or not in $\phi$ ing one acted with the view or intent of $\phi$ ing. The duty to try is satisfied by taking certain actions with the view or intent of $\phi$ ing, regardless of whether or not one in fact succeeded in $\phi$ ing.

In a later publication Gardner claims that this distinction is "as basic as they come"s and key to the distinction between negligence and strict liability. According to Gardner, while strict liability comprises a duty to succeed in not performing the prohibited conduct or causing the prohibited outcome, negligence comprises both types of duties: a duty to try (through intention and reasonable conduct) not to harm, and a duty to succeed in not causing harm. Viewing the negligence standard as predicated on a dual duty — a duty of care and a duty not to harm - is commonly accepted. It is Gardner's specific account of the duty of care as a duty to try (i.e., a duty to act safely ${ }^{4}$ with the view or the intention of averting harm) that is novel.

'Trying' is a complex concept. Under Gardner's account of the duty of care 'trying' seems to mean acting with the intent to achieve a certain result or outcome. According to Gardner, the duty of care in negligence (his 'duty to try') imposes a duty to act with the intent of averting harm. It is, therefore, a duty to "engage in a certain kind of mental activity" as well as a duty to act according to a standard of conduct. ${ }^{5}$

comparative negligence and assumption of risk. See Dan B. Dobbs, The Law of Torts, vol. 1 (St. Paul, MN: Westgroup, 2000) at 493-550.

2. John Gardner, "The Purity and Priority of Private Law" (1996) 46 U.T.L.J. 459 at 486.

3. John Gardner, "Obligations and Outcomes in the Law of Torts" in Peter Cane \& John Gardner, eds., Relating to Responsibility: Essays for Tony Honore (Oxford: Hart, 2001) 111 at 120.

4. To clarify, I say that one must act "safely" only to the extent that one's actions do not generate a risk forbidden by the duty of care. Under most manifestations of the duty of care one's actions need be safe only to the extent that they are not unreasonably risky.

5. Gardner, supra note 2 at 485. 
Gardner essentially construes the duty of care to comprise a conjunctive norm: one must act with reasonable risk and, in so acting, intend to avert harm. It follows that under Gardner's account of the duty of care the negligence standard is breached where harmful conduct either constituted an unreasonable risk or where the actor lacked the mental state he should have had when so acting (or both). In the former case the negligence standard is violated regardless of whether or not one intended to avoid harm. In the latter case, the negligence standard is violated regardless of whether or not one's conduct was reasonable.

\section{B. The Appeal of the Duty to Try}

Although arguably revisionary — as explained below, the prevailing view reflected in the law is that avoiding negligence liability for harmful outcomes does not require intending to avert harm - the account of the duty of care as a duty to try has its appeal. Most importantly, it offers an explanation of the responsibility-component in negligence. It is an account that, as is explained below, addresses how agency and responsibility-capacity relate to negligence liability yet still maintains a view of negligence (i.e., the breach of the duty of care) as conduct alone: not 'sneaking' any 'negligent mental state' into the account of what constitutes a breach of the duty of care.

Relatedly, the idea of the duty to try seems to capture the 'care' in the 'duty of care.' After all, trying to avert harm - in both conduct and intention - seems essential to acting with care. How can one act with care without intending to benefit or at least to avert harm?

In addition, Gardner's account appears to capture and explain the nature of cases wherein the duty of care requires conduct that seems closely tied to and even inseparable from intending to avert harm. For example, consider the case of negligence in rescuing. A voluntary rescuer has a duty towards the rescued to carry out the rescue with reasonable care. ${ }^{6}$ It seems hard to imagine a rescuer doing so without concurrently intending to avert harming the rescued party. The whole point behind an act of rescuing is to avert harm to the rescued, and where one's rescuing actions are reasonable it seems almost inherent that one's rescuing actions were accompanied by an intention to avert harming.?

\section{The Duty to Try and Negligence Responsibility}

Gardner's account of the distinction between negligence and strict liability, and by extension what I characterize as his account of the responsibility-component in the negligence standard, is both elegant and compelling. A responsibility-component in a legal norm is the component in the norm that sets the grounds for legal liability

6. Restatement (Second) of Torts $§ 324$.

7. Section VI develops this idea and explains that while such cases shine a light on the central role that trying to avert harm plays in complying with some instances of the duty of care, they do not for the most part demonstrate that the duty of care gives rise to a duty to try. 
such that they match the grounds for moral responsibility. For example, in the case of intentional torts it is the intentional grounds for liability that match up with the grounds for responsibility (under a theory of moral responsibility that predicates responsibility on an exercise of the will). The question is whether or not the idea of the duty of care as a duty to try offers a compelling account of the responsibilitycomponent in the standard of negligence.

The idea of the duty of care as a duty to try does not challenge the widely accepted tenet that negligence liability does not depend on having any specific mental state. ${ }^{8}$ Unlike intentional torts and crimes, which are based on the coupling of a 'bad' state of mind with certain (restricted) conduct (or omission), negligence is established based on conduct alone: the actor engaged in unreasonable conduct need not have any specific mental state in order to breach the duty of care. According to Gardner, while the negligence standard does not restrict any (positive) mental state, ${ }^{9}$ its duty of care mandates having a specific state of mind (trying to avert harm) when engaged in activity subject to the standard of care. Under this view, therefore, violating the negligence standard is not a product of having a restricted state of mind but rather of failing to have the mandated state of mind (intending to avert harm) while engaged in harmful conduct. While he is willing to concede (for the sake of argument) that "the law does not locate D's negligence in the fact that he tried to do what he tried to do" Gardner argues that the law "[does] nevertheless ... locate D's negligence in what he meanwhile didn't try to do."'10

It is from this proposition that I think Gardner's position derives much of its appeal and elegance. Gardner's account points to the failure of a person (who is subject to a duty of care) to have the mandated state of mind - trying to avert harming those to whom one owes care - as the grounds for that person's liability for his (negligent) conduct. It is an account that grounds negligence liability in what seems like a morally relevant and responsibility-/fault-generating fact-failing to try to avert harm — while still succeeding in complying with the tenet that in breaching the duty of care no 'negligence mental state' is involved, only negligent conduct. It is, in other words, a promising account of the responsibility-component in the standard of negligence.

The puzzle of negligence responsibility is predicated on the strong constituting relation often associated between control (comprising informed intentionality and action) and responsibility (the former constituting the latter) and on the fact that negligent conduct is a product of either unintentional omissions (failing to remember, to do, to realize, to take into account, etc.) or of unintentional actions that are

8. A tenet reflected in the Restatement of the Law. See Restatement (Second) of Torts $§ 282 \mathrm{~d}$ (pointing out that the negligence standard does not address "conduct which creates liability because of the actor's intention to invade a legally protected interest of the person injured or of a third person."). There is a competing minority view according to which negligence involves a mental state of indifference or inadvertence in addition to negligent conduct. For a discussion, see Fowler V. Harper, Fleming James, Jr., \& Oscar S. Gray, Harper, James and Gray on Torts (New York: Aspen, 2007) at 428-32. It is not the position I take here.

9. The duty of care does, according to Gardner, restrict not having the mental state comprised in 'trying'. Yet, I do not think that not having a mental state is a mental state.

10. Gardner, supra note 3 at 119. 
the product of failed intentional actions (accidents, mistakes, etc.), both characterized by a lack of control, intent and awareness. Negligent conduct (i.e., a breach of the duty of care) is not intentionally or knowingly negligent. In negligence, therefore, by definition one does not control, guide or intend to act negligently nor is aware of one's negligence. How then, we ask, is one responsible for one's negligent conduct and its harmful outcomes? After all, one does not intend not to intend or control one's failure to control. Negligence liability seems to attach where while an actor's conduct is wrongful (in breach of the duty of care) the actor herself is not at fault or responsible for her wrongful conduct. In fact, some influential legal theorists have accepted that accident law and negligence liability do not necessarily involve fault or (moral) responsibility, ${ }^{11}$ claiming that negligence law should allocate liability according to moral principles other than moral responsibility.

Gardner, in contrast, does not 'give up' on moral responsibility in negligence. His account of the duty of care as a duty to try is, in essence, an account of the responsibility-component in negligence and, in effect, a plausible beginning of an answer to the puzzle of negligence responsibility. After all, Gardner offers his account to explain how the negligence standard, which requires fault and responsibility for its violation, differs from the strict liability standard, which does not require fault and responsibility for its violation. ${ }^{12}$ The question is what in the negligence standard accounts for this correlation between breach and responsibility or, put differently, what is the responsibility-component in the negligence standard?

If negligence indeed includes or entails responsibility, it must follow that people's agency, or more specifically their capacity for responsibility, plays a role in the negligence standard. ${ }^{13}$ Moral responsibility for conduct is a function of a relation between an agent's responsibility-capacities and her conduct. One's responsibilitycapacities must somehow engage, exercise or relate to one's conduct in order for one to be morally responsible for that conduct. Rational agents are capable of understanding facts, reasons, and norms and of deliberating and reaching decisions regarding those facts, reasons, and norms.$^{14}$ Responsibility-capacity comprises the powers constitutive of rational agency, primarily the capacities to reason and understand $^{15}$ (including capacities for memory, decision, attention, perception and judgment as well as possessing certain knowledge). Moreover, to exercise one's responsibility-capacities certain knowledge and awareness of the circumstances

11. Jules L. Coleman, Risks and Wrongs (Cambridge: Cambridge University Press, 1992) at 217 20; Tony Honore, "The Morality of Tort Law-Questions and Answers" in David G. Owen, ed., Philosophical Foundations of Tort Law (Oxford: Clarendon Press, 1995) at 73-96, 88-90 (suggesting - based on retributive reasons [or rather the lack of such reasons] -insurance as a mechanism for fair distribution of the costs of compensation in cases of no-fault torts, including negligent actors who lacked the capacity of a reasonable person); Roscoe Pound, An Introduction to the Philosophy of Law (New Haven, CT: Yale University Press, 1954) at 91 (viewing the fault requirement in negligence as a "dogmatic fiction").

12. If responsibility had no role in negligence, negligence would be similar to strict liability. See Hart, supra note 1 at 154-55.

13. Hart, ibid. at 154-55.

14. See ibid. at 227.

15. Joseph Raz, "Being in the World-Reading Version", http://sites.google.com/site/josephnraz/ agency,responsibilityandluck (revised version forthcoming in Ratio, 2010). 
and nature of one's conduct are required. Generally, people are responsible if and only if they possess a capacity for rational action ${ }^{16}$ and are only responsible for actions related to their rational capacity. ${ }^{17}$ The capacity to control one's conduct and to act based on one's decisions enables the expression of rational capacity in action. The question is what is the nature of the responsibility-grounding relation between agency and conduct in the case of negligence?

The conception of the duty of care as a duty to try offers an account of what seems like a responsibility-grounding connection or relation between an agent's responsibility-capacities and the type of conduct mandated under a duty of care. The agent's capacities for responsibility are engaged and challenged by the duty to control or to guide her conduct with the view or intention of averting harm. And, breaching the duty of care is a function of failing to try - through action or omission (comprising both conduct and intent) - to avert harm. It appears that the elements of breaching the duty of care - failing to try — relate to the actor's responsibilitycapacities so as to align legal breach and liability with moral responsibility.

However, if responsibility is indeed a function of some informed exercise of people's responsibility-capacities in relation to those actions for which they are responsible, then it is not clear in what way these capacities are exercised by failing to try to avert harm. As pointed out above, negligence occurs where one's failure to meet one's duty is unintentional, accidental, inadvertent or unknown. In other words, what characterizes breaches of the duty of care is the disengagement of one's responsibility-capacities with one's breaching conduct. Thus, it appears that responsibility for breaching a duty of care cannot derive from a failure to try to avert harm because the failure to act with a certain intention is never a product of the exercise or engagement of one's responsibility-capacities. In other words, even if negligently failing to comply with a duty may ground legal liability it does not seem to ground one's responsibility for violating the duty. Moreover, the fact that one could have been responsible for complying or for failing to comply with one's duty of care-had one exercised one's agency in relation to one's duty and intentionally or knowingly acted or omitted, or that one could have been aware of the wrongful nature of her conduct but negligently was not - does not entail that one is in fact responsible for unintentionally, inadvertently or unknowingly failing to satisfy the duty. After all, that we could have intended to $x$ and that we could have known $y$ does not entail that we intended not to intend to $x$ or not to know $y$. Thus, under a control- or intention-based approach to responsibility, equating the duty of care with a duty to try does not offer a satisfying explanation of the responsibility-component in negligence: the grounds for negligence breach and liability-failing to try-do not match the grounds for negligence responsibility. Thus, it may seem that the idea of the duty of care as a duty to try does not give us an account of the responsibility-component in the standard of negligence.

If, however, we reject control or intention or awareness as a necessary condition for responsibility, the account of the responsibility-component in negligence that 
I think is implicit in the theory of the duty of care as a duty to try is perhaps sustainable, pending a corresponding theory of responsibility that can explain how one is responsible for unintentional conduct or omissions (such as negligently failing to try to avert harm). Such an alternative theory of responsibility would bring the grounds for negligence responsibility in line with the grounds for breach and legal liability under the theory of the duty of care as a duty to try.

When coupled with such an alternative theory, conceiving of the duty of care as a duty to try proves illuminating. The duty to try grounds negligence liability in the failure to try (through coupling intention and conduct) to avert harm, which may function as a responsibility-component in the negligence standard under a theory accounting for how the failure to properly exercise one's responsibility-capacities in the case of negligent conduct — such as failing to try to avert harm - can ground moral responsibility for that conduct (or omission).

It so happens that there are such alternative or supplementary approaches to moral responsibility. One is found in Joseph Raz's recent work on responsibility. ${ }^{18}$ Raz argues for a "rational functioning principle"19 of responsibility according to which "conduct for which we are (non-derivatively) responsible is conduct which is the result of the functioning, successful or failed, of our powers of rational agency." ${ }^{20}$ Negligence responsibility is therefore predicated on what Raz calls "malfunctions" of the agent's rational capacities. Negligence responsibility for an unintended omission or for a failure to properly perform an intended action, which is within one's "domain of secure competence," ${ }^{21}$ arises where it occurs due to a malfunctioning in the agent's powers of rational agency. It is the failure or malfunction of one's responsibility-capacities to perform as they could and should have that grounds negligence responsibility.

That a malfunctioning or failure of one's responsibility-capacities to guide or control one's actions may ground an agent's responsibility for her conduct derives from the significance the successful functioning of our agency has in our life and for our identity. As Raz puts it "[t]he way we feel about ourselves, our self-esteem, our self-respect, the degree to which we are content to be what we are, or what we perceive ourselves to be, our pride in ourselves, our shame in how we are or in how we conduct ourselves - all these and various other self-directed attitudes and emotions, depend in part on competence in using our rational faculties." ${ }^{22}$ In other words, certain failures of our rational agency (and their outcomes) contribute to defining who we are, thereby attaching us to the conduct and outcomes we-as rational agents - are responsible for.

A second alternative approach to explaining negligence responsibility is that of George Sher, ${ }^{23}$ who approaches the puzzle of negligence responsibility from an

18. Joseph Raz, "Responsibility and the Negligence Standard," Columbia Public Law Research 09207 available at SSRN: http://ssrn.com/abstract=1436022 (revised version forthcoming in Oxford Journal of Legal Studies 30 (2010) 1-18).

19. Joseph Raz, "Agency and Luck," (Draft, 12 Oct. 2009).

20. Raz, supra note 18 at 5 .

21. Ibid. at 23 .

22. Ibid. at 22. See also Raz, supra note 19; Raz, supra note 15

23. George Sher, Who Knew? Responsibility Without Awareness (New York: Oxford University Press, 2009). 
epistemic angle. Sher asks how can we hold a person responsible for conduct one should have been aware was wrongful but in fact lacked such awareness. It seems one cannot exercise one's agency in a way that makes one responsible for one's wrongful conduct if one is unaware of the wrongful nature of one's conduct. As was stipulated above, responsibility is grounded in a relation between the exercise of one's responsibility-capacities and one's conduct. And, in order for one's responsibility-capacities to engage with one's wrongful conduct so as to ground responsibility, certain knowledge and awareness of the nature of one's conduct is required. What characterizes cases of negligence is a lack of awareness that one is acting negligently. How then is negligence responsibility possible?

According to Sher, responsibility for a failure to be aware of the wrongful nature of one's actions - where one could have been so aware - arises if the failure to detect the wrongness of the conduct "is both defective in relation to some applicable standard ('he should have realized') and due to some combination of his own constitutive attitudes, dispositions and traits. ${ }^{24}$ In such circumstances there is a clear connection between the agent - as she is as a whole considering the constitutive properties of her character and nature - and her failure to realize or deduce the wrongness of her conduct from her knowledge and circumstances that allow for such a realization. ${ }^{25}$ Here, negligence responsibility is a function of the boundaries of the self: when the failure to appreciate the wrongful nature of one's actions is a product of attitudes, dispositions and traits that are constitutive of who one is, responsibility for one's wrongful conduct arises from one's failure to appreciate the wrongful nature of one's actions and attaches to that person. ${ }^{26}$

The theory of the duty of care as a duty to try fits nicely with both these alternative approaches to moral responsibility in negligence. Both Raz's and Sher's theories offer, mutatis mutandis, an account of when an unintentional failure to act with care grounds responsibility. These theories explain how an agent can be responsible for conduct that was beyond her control, will or awareness. And thus, both theories can morally ground negligent liability that derives from a failure to meet one's duty to try under the negligence standard. In such alternative theories of responsibility there is an overlap between the grounds of legal breach and liability under Gardner's theory - failing to try - and the grounds for responsibility for breaching the duty of care. Thus, the duty to try may function as the responsibilitycomponent in the negligence standard: it accounts for how negligence involves responsibility and fault and for how the negligence standard differs from the strict liability standard.

Nevertheless, even accepting that the notion of the duty of care as a duty to try fits well with a nonexclusively control- or will-based theory of moral responsibility, the idea that the duty of care incorporates a duty to intend to avert harm is highly problematic. In the following three sections I demonstrate why, as a matter of both description and prescription, the concept of the duty of care does not and should 
not incorporate a duty to intend to avert harm (be it a categorical or a de facto duty), concluding that the failure to try does not and should not ground negligence liability. This in turn entails that while a promising view, the responsibility-component in the negligence standard is not a duty to try. After establishing this proposition I will, drawing on the themes discussed above, offer an alternative account of the responsibility-component in the standard of negligence.

\section{Flaws in the Characterization of the Duty of Care as a Duty to Try}

Gardner's theory does not comport with the concept of negligence in the core of legal negligence. Moreover, tailoring the negligence standard to fit Gardner's approach may have harmful effects: first, a duty to have a specific intent or mental state accompany one's conduct can curtail autonomy and the liberty of thought protecting autonomy, as well as other values; second, such a duty is often counterproductive to the core end of the duty of care-averting (negligent) harm; third, incorporating a duty to try into the law of negligence would raise probative difficulties that make it both improbable and undesirable. Therefore, from the perspective of positive law, the idea of the duty of care as a duty to try is neither descriptively accurate nor prescriptively desirable.

\section{A. Avoiding (Legal) Negligence Liability Without Trying or Intending}

If descriptive, the hard case for Gardner's version of the negligence standard is where negligence is avoided while one violates both aspects of Gardner's version of the standard of negligence: causing harm as well as failing to try to avert it.

That the negligence standard includes an obligation to $\phi$ (Gardner's duty to succeed), or in other words not to harm, is indisputable. One cannot violate the standard of negligence without causing injury or damage; after all there is no liability in negligence without causing negligent harm or bringing about some other restricted outcome. So much is clear.

In contrast, legal negligence does not seem to include a duty to try. Generally in the law, duties of care in negligence are breached by "conduct that creates or fails to avoid unreasonable risks of foreseeable harm to others." ${ }^{27}$ The content of the legal standard of care most often derives from the reasonably prudent person standard, ${ }^{28}$ although there are other standards applied to particular types of conduct such as practicing law ${ }^{29}$ or medicine. ${ }^{30}$ Nothing here admits of a requirement to try. In the law, one's conduct may be reasonable (satisfying the duty of care) whether or not, in so acting, one tried to avert harm. The reasonably prudent person standard

27. Dobbs, supra note 1 at 275.

28. Harper, supra note 8 at 432.

29. In the case of attorney malpractice, the 'special' standard of care requires exercising the competence and diligence normally exercised by lawyers in similar circumstances. Restatement (Third) of the Law Governing Lawyers $\S 52$.

30. The standard of conduct in medical malpractice is based on a professional-peer standard. See Dobbs, supra note 1at 631. 
looks to what the reasonably prudent person would have done (or omitted from doing) under similar circumstances, not to what he or she would have tried or intended to do under such circumstances.

The weaker flank of Gardner's version of the dual-duty account of the negligence standard appears to be, therefore, his account of the duty of care: insisting that the duty of care is a duty to try. But which half of Gardner's duty to try is at fault? As explained above, the duty to try comprises a conjunctive norm: one must act with reasonable risk as well as intend, in so acting, to avert harm. The question is can one who is subject to a duty of care and has caused harm avoid being negligently liable while having failed to try, i.e., either having failed to act with reasonable care or having failed to intend to avert harm. While reaching the threshold of reasonable conduct seems a necessary condition for avoiding negligence liability for harming, one who causes injury may still avoid liability in negligence if one's conduct was sufficiently safe, regardless of whether or not one acted with the intent to avert bringing about the harm. In fact, one may avoid violating the negligence standard by acting reasonably — satisfying the duty of care - for any number of factors, reasons or intentions, such as aesthetic, how one was brought up, how one is 'wired' and so on.

This remains the case even where one's conduct is intentional. Where one $\phi \mathrm{s}$ it is often the case that one intends to $\phi$. However, even if $\phi$ ing constitutes reasonable conduct it is not always the case that by intending to $\phi$ one also intended for one's actions to be reasonable or to avoid harming. In $\phi i n g$ one may have any number of intentions, of which safety is an unintentional byproduct. For example, one may run into the road after one's ball and look (intentionally) right and left in search of the ball. Under such circumstances one would unintentionally meet one's legal duty to keep a lookout for danger when crossing the road ${ }^{31}$ because one would be aware of the traffic, even though that awareness would not be a product of or accompanied by an intention to avert harm, but rather a product of searching for the lost ball. Gardner's account of the duty of care is, therefore, equally inapplicable to cases of intentional and even planned conduct, which turn out negligent, as it is to cases of unintended omissions or accidental negligent conduct. In both types of cases one may fail to intend to avert harm and still avoid violating the negligence standard as long as one's conduct meets the standard of care.

Even one who intends to engage in hazardous behavior yet in fact mistakes the hazardous course of action with the safe course of action is not responsible for negligent harm, even if he is subject to a duty of care and his (reasonably safe) actions have harmful effects. For example, imagine a patient with two diseased fingers. The more diseased finger is beyond cure, but the patient's other finger will heal if the more diseased finger is amputated. There is, however, a $10 \%$ chance of losing the less diseased finger due to risks inherent in the operation, even if its execution is impeccable. The surgeon, who harbors a grudge against the patient, maliciously amputates what he believes is the patient's less diseased finger with the intention

31. See Hennings v. Schufeldt, 222 Neb. 416 at 422-23 (1986) (A pedestrian crossing a road between intersections without looking out for passing traffic was found negligently liable for causing his collision with a passing motorbike). 
of causing the patient to lose his likely chance of saving it. However, if earlier a nurse had mistakenly marked the less diseased finger for amputation and, as a consequence, the vindictive surgeon had inadvertently amputated the correct finger, i.e., the more diseased one, the doctor would clearly not be liable in negligence, even if the patient were to end up in the unlucky $10 \%$ of those who still lose the less diseased finger due to risks inherent in the prescribed operation. In other words, failing to intend to avert harm by intending to cause harm does not amount to a violation of the negligence standard even if one causes harm (e.g., by performing an operation) so long as the harm causing conduct was reasonable according to the reasonably prudent person standard. ${ }^{32}$

To sum up, in the law failing to couple one's conduct with intent or a view to avert harm is neither a necessary nor a sufficient condition for violating the duty of care in negligence. Therefore, the failure to couple intention and conduct so as to combine 'trying' cannot function as a condition for breaching the duty of care. Thus, Gardner's account of the duty of care does not capture the doctrine of legal negligence.

Gardner is of course aware of this doctrine-driven objection to his theory, yet maintains that this doctrinal approach does not capture the "real legal position". In support, he offers a semantic analysis of the term 'care.' Gardner observes that the whole point of the tort of negligence is that one "didn't take sufficient care to avert (limit, reduce, control) the injurious side effects of his endeavors." ${ }^{34}$ And because "[t]aking care is an essentially intentional action ... [o]ne cannot take care not to $\phi$ without trying not to $\phi . "$ " "The words "to avert," Gardner goes on to observe, "mean 'in order to avert,' 'with a view to averting,' or (in other words) 'intending to avert'. ', ${ }^{36}$ Gardner concludes that the duty of care imposes an obligation to act according to a certain standard of care with the intention or view of meeting that standard or of averting harming.

Gardner's method for defending his position that there is a categorical duty to try in the negligence standard's duty of care is problematic. As demonstrated above, Gardner's natural language or plain-meaning analysis of the term 'care' as an intentional concept does not correspond to the use of the term 'care' in the context of legal negligence, which relies on an objective standard of conduct. When attempting to delineate the meaning of a term within a certain context, one should explore how that term is in fact used in that context. Supplanting a meaning of a term from another context is artificial. The better course for exploring the meaning of the term 'care' is to look to its use in the legal discourse of the concept of negligence. The duty of care in negligence focuses on conduct and action alone and not on the intention driving, guiding or accompanying them. Gardner introduces into the legal discourse of negligence the common use of the term 'care,' which indeed usually does

32. See Dobbs, supra note 1 at 276 ("The defendant who intentionally takes a risk may or may not be negligent").

33. Gardner, supra note 3 at 119.

34. Ibid. at 119-20.

35. Ibid at 120 [emphasis added].

36. Ibid. 
imply intent. Nevertheless, legal use often does not fully correspond to the meaning the same term has in natural language nor in other contexts. For example, legal causality, which includes a foreseeability component, differs from a Newtonian conception of causality that relies solely on a cause-in-fact principle. Similarly the concept of 'legal truth,' which is a function of the rules of evidence, differs from other conceptions of truth. That the same is true of 'care' in the legal 'duty of care' is not surprising.

Thus, if Gardner's account of the duty of care as a duty to try is taken as an account of the legal manifestation of the negligence standard, it is simply mistaken as a matter of positive law.

If, however, we take Gardner's theory as a prescriptive revisionary account for the form the duty of care should take, its inconsistency with the legal practice of negligence is of course not a conclusive reason for rejecting it. If revisionary, a different form of refutation is called for-specifically, one explaining why adopting the revisionary approach is undesirable. Arguably, considering that the legal scrutiny, reflection, refinement and practical testing of the concepts of negligence and of a duty of care are unparalleled, the fact that Gardner's account of these concepts does not correspond to the legal practice of negligence is a strong (even if not a conclusive) reason for doubting the validity of viewing the duty of care as a duty to try. Still, positive law is not always justified or desirable.

\section{B. Mandating Intentions: The Harmful Effects of the 'Duty to Try'}

Should the legal duty of care in negligence comprise a duty to try? If the duty of care is construed as a duty to try, it follows that the duty of care mandates coupling a specific intention or view (to avert harm) with conduct that is reasonable. It is, as Gardner puts it, a duty to engage in a certain kind of mental activity, ${ }^{37}$ which is a duty to have a certain mental state. This is a peculiar duty for modern legal systems as well as for liberal morality. In regulating actors' mental states or mental activities the law usually restricts actors from coupling certain specific types of mental states with certain conduct, implicitly permitting all other mental states. For example, the Uniform Fraudulent Transfer Act defines "[a] transfer made or obligation incurred by a debtor" as fraudulent "if the debtor made the transfer or incurred the obligation with actual intent to hinder, delay, or defraud any creditor of the debtor." ${ }^{38}$ An additional example is shooting at another with the intent of killing, which constitutes an attempt at murder. ${ }^{39}$ Transferring funds without an intent to defraud one's creditors does not amount to fraudulent transfer under UFTA $\S 4(a)(i)$ - no matter what the person may have been thinking at the time - just as shooting at another person without the intent to kill — no matter what one's intentions were otherwise - is not criminalized by the prohibition of murder. In Gardner's

37. Gardner, supra note 2 at 485.

38. UFTA $\S 4(\mathrm{a})(\mathrm{i})$.

39. Under New York law a person is guilty of murder in the second degree when, with intent to cause the death of another person, he or she causes the death of such person or of a third person. N.Y. Penal Law $\S 125.25(1)$ [emphasis added]. 
version of the duty of care the normal order is reversed - the obligation is to have a prescribed particular state of mind or mental state accompany a certain type of action. There is something off-putting and prima facie suspect, at least for those of liberal sentiments, with the notion of a duty to have a specific type of mental state, more so even in the case of legal duties.

Gardner's insistence on construing the duty of care as a duty to have a specific mental state gives rise to several more specific objections. First, the liberty of thought is a fundamental safeguard of autonomy. For the most part legal duties regulating mental states are negative in nature - restricting fairly narrowly defined types of thoughts or intentions and only when coupled with certain types of conduct. These are usually fairly minor intrusions on the liberty of thought and autonomy. In contrast, mandating specific types of thoughts and intentions significantly curtails the liberty of thought as well as directly adversely impacts personal autonomy by mandating people have certain mental states regardless of their will. This is true for moral principles and is certainly true where legal sanctions enforce the duty. These negative implications are specifically acute in the case of the negligence standard, instances of which (both morally and legally) regulate numerous practices and aspects of people's everyday activities, actions and choices. Modern life comprises countless potentially risky practices: driving, preparing food, crossing the road, getting on a crowded train, installing an air conditioner in a high-rise building and so on. Such risky practices give rise to a moral duty of care and often justify a legal duty of care. Under Gardner's account, generating a reasonable risk or acting with reasonable care when subject to a duty of care does not suffice to meet the demands of the duty. One must not only install the air conditioner, drive, or cross the road with reasonable risk or care but must also do so with the view of averting negligent harm. Because the negligence standard covers so many aspects of everyday life, Gardner's account of the duty of care has potentially crippling implications for liberty of thought and personal autonomy.

Infringement of the liberty of thought inherent in Gardner's approach poses a second danger. It risks curtailing having other valuable intentions and mental states (but for the required intention to avert harm). The capacity for having multiple intentions, experiences and mental states in general is limited. First, acting with the intent to avert harm is not always compatible with concurrently having other valuable intentions, experiences and other mental states. For example, a giddy state of mind and intentionally taking care to avert harm seem incompatible. Second, people have limited powers of cognition, reflection and thought. Preoccupation with averting harm might not always allow for simultaneously having other valuable mental states. Thus, both these potential consequences can impose even greater restrictions not only on the liberty of thought - thereby limiting personal autonomy — but also on various other aspects of people's welfare, such as limiting valuable experiences, emotions, interaction with others, self-reflection and so on. For example: listening to and singing along with an opera recording while preparing pasta for a party instead of worrying about not accidentally poisoning one's guests.

While not all intentions are experienced in such a 'pronounced' or 'articulated' manner, some are. I expect this to be more so the case when the actor is subject 
to a known sanction-backed duty to have a specific type of intention. This would certainly be the case where actors accustomed to performing with reasonable care (without intending to avert harm) are suddenly required by law to so intend. And, the more 'pronounced,' 'articulated' or experienced one's intentions are the more disruptive the duty to have them becomes.

Moreover, insisting that an actual intent or view to avert harm accompany potentially risky conduct is, at times, counterproductive to preventing harm, which is the raison d'etre of the negligence standard. Many actions are better just performed, without an accompanying intention (beyond the intention to perform the action itself). Preoccupation with one's reasons for taking an action and with the perils inherent in the action can derail one's ability to best perform the action. Attention to care and preoccupation with preventing the harms inherent in risky activity is usually advisable and characteristic of the process of learning how to safely carry out potentially risky practices and activities. Once the safe pattern of conduct is mastered, the mental state of trying or intending to avert harming often disappears for the most part and 'naked' conduct takes over. Insisting on a duty to try on prudential grounds - thinking that if people intended to avert harm less harm would occur - is not, therefore, always sound. Considering that the essence of duties of care is the prevention of harmful unreasonable conduct, an account of negligence that derails that very end, such as the idea of a duty to try, is suspect.

Adopting an awareness-based conception of intent does not remove the difficulties with Gardner's approach. Generally, one should not confuse intent with desire - it is possible to intend something without wishing or desiring it. ${ }^{40}$ In the law it is not uncommon to impute 'intent to wrong' to a person who was fully aware of the probable harmful outcomes of his actions, even if he did not actually mean or wish to bring about those outcomes. H.L.A. Hart gives the example of the common-law case of R. v. Desmond, Barrett and Others ${ }^{41}$ where the defendant, in an attempt to free two incarcerated prisoners, dynamited the prison wall and consequently caused the death of bystanders. ${ }^{42}$ The court found that although Barrett did not wish to harm anyone he nevertheless had the required intent for a charge of murder, which required a mens rea of malice aforethought, because Barrett knew that killing bystanders was a highly probable outcome of his intentional actions. As Hart puts it: "[F]or the law, a foreseen outcome is enough, even if it was unwanted by the agent, even if he thought of it as an undesirable by-product of his activities". ${ }^{43}$ Even if we do not accept the position that all highly foreseeable side effects are "intended" 4 _ for example, in taking the ferry to Ellis Island I know I will be seasick, and still by intending to take the ferry I do not intend to be seasick-awareness of a likely outcome of one's conduct still often seems sufficient

40. John Finnis, "Intention in Tort Law" in Owen, supra note 11 at 236.

41. (1868) 11 Cox C.C. 146, C.C.C.

42. Hart, supra note 1 at 119-20.

43. Ibid. at 119 .

44. The criminal law, for example, distinguishes between purpose and knowledge. See Model Penal Code $\S 2.02(2)$. 
to impute responsibility and liability for causing the outcome. ${ }^{45}$ In this understanding of 'intending,' complying with a duty to try only requires acting with reasonable care or generating reasonable risk while one is aware that one is so acting.

This less stringent notion of 'intent' does not, however, rehabilitate Gardner's account of the duty of care. Even though on occasion it is less burdensome to freedom of thought and personal autonomy, this interpretation of the duty to try still does not comport with the legal practice of negligence. Clearly, one may avoid negligence liability even if one is unaware that one's conduct is reasonable. Moreover, this softer approach to intentions does not deliver the 'care' Gardner insists on. As we saw, Gardner believes that a duty to care inherently requires one to act with the view of averting harm. Merely knowing that one's actions are sufficiently safe does not amount to acting with 'care.' Lastly, interpreting Gardner's duty to try in this way generates an unusual duty, considering that knowledge is usually a factor in imputing responsibility and liability, not in avoiding it.

\section{Problematic Probative Implications}

Finally, the probative hurdles a duty to try would generate make it an improbable and mostly ineffective component of legal negligence. Under the idea of a duty of care as a duty to try, an actor who is subject to a duty of care and who causes harm through reasonable conduct is still liable in negligence if she failed to try to avert the harm, i.e., if in acting with reasonable care she did not also intend to avert harm. Barring a confession, however, proving a lack of intent to avoid harm where one's conduct was reasonable is very difficult. Under a conception of the legal duty of care as a duty to try, the significance of proving a lack of intent to avert harm arises primarily where an actor, subject to a duty of care, causes harm to a member of a protected class through reasonable conduct. Here, proving a breach under a conception of the duty of care as a duty to try must rely on establishing a lack of intent to avert harm. Considering that the strongest mark of the nature of one's intentions is one's conduct - which would mostly make proving a failure to intend functionally dependent on establishing unreasonable conduct - proving a breach of the duty of care in cases of reasonable conduct would most likely prove extremely difficult and even impractical. Thus, it is not clear what practical impact a standard of care requiring intent to avert harm would have.

\section{Conclusion}

To sum up, construing the duty of care to comprise a duty to try does not correspond to legal doctrine and is unadvisable as a prescription for legal revision. A duty to try in negligence is overly burdensome to autonomy and liberty of thought,

45. According to Kimberly Ferzan, cases wherein foreseeable side-effects are intended are instances of 'inseparable effects.' An effect $A$ is 'inseparable' from effect $B$ when an intention to $A$ incorporates by its nature an intention to $B$. When exactly such a relation arises is a complex matter, which Ferzan explores. Kimberly Kessler Ferzan, "Beyond Intention" (2008) 29 Cardozo L. Rev. 1147. 
potentially disruptive to valuable experiences, and at times counterproductive to harm prevention. Moreover, if adopted as a legal duty, the duty to try would often raise practically insurmountable probative hurdles making for an improbable and often ineffective legal standard.

\section{Conduct and Intent: A de Facto Duty to Try?}

Accepting that the duty of care in negligence does not and mostly should not include a categorical duty to intend to avert harm - thereby ruling out equating the duty of care with a duty to try - let us next turn to exploring the proposition that, at times, the duty of care incorporates or rather gives rise to a de facto duty to try. According to this proposition, intending to avert harm is often, as a matter of psychological or sociological fact, a practical necessary condition for generating the conduct the duty of care requires. The validity of this proposition turns on the factual observation that there are cases in which it is presumably either impossible or highly improbable to act with reasonable care or to comply with the specific conduct requirements of a specific duty of care without concurrently intending to avert harm. Therefore, the proposition equating the duty of care with a duty to try is neither doctrinal nor prescriptive but descriptive. As explained above, some of the appeal I find in conceiving of the duty of care as a duty to try derives from its purported ability to explain what appears to be 'really' going on in certain cases, regardless of the legal doctrine. That the duty of care may, in certain cases, give rise to a de facto duty to intend to avert harm partially rehabilitates the descriptive virtues of the position that the duty of care is a duty to try.

Explored below are the two types of cases that appear most of all to entail such a de facto duty to intend to avert harm. The first is where coupling action with intent to avert harm is the most prudent course by which a particular person may comply with a standard of conduct. The second is where the specific type of conduct a specific duty of care mandates seems to inherently incorporate intending to avert harm.

My challenge to the idea of a de facto duty to try is based on pervasive counterexamples. A de facto duty to try entails that - as a matter of factual necessity or probability - failing to intend to avert harm will most likely lead to or necessarily go hand in hand with a failure to act with reasonable care. I argue that in both types of cases mentioned above and explored below an actor may satisfy the duty of care without intending to avert harm but rather through mimicking others or following and complying with custom, experience, example, order and policy. Considering that such practices are ubiquitous they give strong reason to doubt whether the duty of care indeed often gives rise to a de facto duty to try, even in cases where prudence suggests one intend to avert harm in order to avoid liability or where a duty of care mandates conduct that appears to require such an intention. Of course rejecting the account of the duty of care as creating a de facto duty to try does not entail that intending to avert harm has no role to play in complying with the negligence standard. Actors are still often advised to so intend as the best means to avoid negligence liability. Yet, mere prudence does not give rise to a duty. 
As suggested above, often the most prudent method for avoiding negligence liability and breaching a duty of care is to intend for one's actions to avert causing harm or to act with the view of averting harm. For example, an electrician rewiring a factory's electrical system is most likely negligently liable for harms caused by faulty wiring if the electrician failed to inspect his equipment or did not check whether the type of wire he installed was suitable for the current used in the factory. Had the electrician acted appropriately — employing the proper safety precautions - it is most likely he would have done so with an intention to avert causing harm.

Consider a second example from the field of liability for product design defects (which follows a standard similar to the negligence standard ${ }^{46}$ ). In order to meet a duty of reasonable care it was held that a design of a staircase escalator must have incorporated safety guards that protect against the foreseeable harm to small children whose fingers might get caught in the space between the end of the escalator and the descending steps. ${ }^{47}$ Under these circumstances, in complying with such a duty of care it seems that, as a matter of prudence, a designer should intend for her design to avert harm. If the designer does not so intend, the probability that she will incorporate childproof safety guards into the design will be very small. Under such circumstances, the idea of a duty to intend - as a de facto duty - appears plausible.

Another seemingly compelling type of case that appears to include a de facto duty to try is where part of the specific type of conduct a duty of care mandates is implementing, planning and reflecting on safety practices when performing a certain type of potentially risky conduct. Such specific standards of care have been developed by courts tailoring specific requirements for specific types of conduct. Another source for such specific standards of care is statutory norms that give rise to standards of negligence per se. In some such cases, where a duty of care requires specific forms of conduct, it is negligent to fail to take certain safety-related considerations into account or to follow a certain method or prudent decision-making process, or to implement certain specific safety-oriented practices.

It is often tempting to think of such specific duties of care, which require specific action of a safety-oriented nature, as including a de facto duty to intend to avert harm. After all, in such cases intending to avert harm seems inherent in the practice of taking safety considerations into account or in instituting procedures or practices oriented towards safety. For example, a duty of care mandating applying the Hand Formula in a deliberation on whether or not to engage in a certain potentially risky activity as a condition for acting with reasonable care may seem to incorporate a duty to act with the intention or view of avoiding harm. ${ }^{48}$ Engaging in the calculations

46. "A manufacturer of a chattel made under a plan or design which makes it dangerous for the uses for which it is manufactured is subject to liability to others whom he should expect to use the chattel or to be endangered by its probable use for physical harm caused by his failure to exercise reasonable care in the adoption of a safe plan or design." Restatement (Second) of the Law of Torts $\S 398$.

47. Reynolds v. May Department Stores Co., 127 F.2d 396 (8th Cir. 1942).

48. The Restatement of the Law of Torts (Third) does not define negligence as requiring actually applying the Hand Formula. However, it does suggest the Hand Formula as a "primary factor" for ascertaining negligent conduct: "A person acts negligently if the person does not exercise 
of the Hand Formula constitutes an activity directed at the avoidance of unreasonably risky conduct that, by extension, seems to inherently include an intention to avoid negligent harm. How can one reflect on the likelihood of causing harm and on the severity of the harm, as well as calculate whether safety precautions are warranted, without intending to avert harm or at least intending to avert negligent harm? Other examples of more specific standards of care which seem to incorporate an intention to avert harm are: the duty to stop, look and listen when crossing a railroad track; ${ }^{49}$ a manufacturer's duty to stay abreast of recent safety-related scientific developments ${ }^{50}$ an electric company's duty to use every accessible protection to insulate its wires at all points where people have the right to go and to use the utmost care to maintain them. ${ }^{51}$ Cases of negligence per se offer further examples: a drug manufacturer's duty to immediately report all unexpected adverse reactions to the FDA; ${ }^{52}$ or a vendor's duty not to sell alcohol to minors. ${ }^{53}$ In all these cases it appears likely that performing the required safety-oriented conduct would be coupled with an intention or view of averting harm.

Nevertheless, even in the case of duties to engage in specific types of safetyoriented practices or where prudence suggests intending to avert harm as the best means for one to comply with a duty of care, the duty of care mostly does not give rise to a de facto duty to intend to avert harm. It often remains possible to take safety-oriented considerations into account and employ safety-oriented measures, practices, procedures, and decision-making processes - thereby complying with a duty of care-without concurrently intending or even realizing that in so doing one would likely avert harming.

Central types of examples of how often intending to avert harm is simply not a necessary element in taking into account safety-oriented considerations, or of

reasonable care under all the circumstances. Primary factors to consider in ascertaining whether the person's conduct lacks reasonable care are the foreseeable likelihood that the person's conduct will result in harm, the foreseeable severity of any harm that may ensue, and the burden of precautions to eliminate or reduce the risk of harm." Restatement (Third) of the Law of Torts: Liability for Physical Harm $\S 3$ (Proposed Final Draft No. 1, 2005). Such a requirement may suggest that as a matter of fact - even if not categorically - the duty of care requires implementing the considerations constitutive of the Hand Formula. The Hand Formula finds an actor negligent "if the burden of taking adequate precautions against the harm is outweighed by the probable gravity of the harm multiplied by the probability that the harm will occur". Black's Law Dictionary 732 (8th ed. 2004).

49. See Baltimore \& O. R. Co. v. Goodman, 275 U.S. 66 at 70 (U.S. 1927) (J. Holmes) (A victim whose truck was struck by a train was found negligent in causing his own death by failing to establish whether a train was approaching before crossing the railroad tracks).

50. See Micallef v. Miehle Co., Div. of Miehle-Goss Dexter, Inc., 39 N.Y. 2d 376 at 386 (N.Y. 1976) ("Also relevant, but by no means exclusive, in determining whether a manufacturer exercised reasonable skill and knowledge concerning the design of the product is whether he kept abreast of recent scientific developments").

51. See Thompson v. Lamar, 322 Mo. 514 at 541 (Mo. 1929) ("An electric light and power corporation, whether private or municipal, is chargeable with negligence per se in maintaining uninsulated, or defectively insulated, wires at a place where it has reason to anticipate that persons may lawfully and rightfully be, and where such persons may likely come in contact with its wires").

52. See Stanton v. Astra Pharmaceutical Products, Inc., 718 F. 2d 553 at 560 (3d Cir. Pa. 1983).

53. See Crowe v. Gaston, 134 Wn. 2d 509 (Wash. 1998) (A court found that a commercial vendor owed a duty of care to the injured party based upon the violation of a Washington statute forbidding the sale of liquor to a minor). 
implementing proper decision-making processes and applying safety-oriented practices are: mimicking others, following custom, or conforming to market and social standards. Mimicking or following the (reasonable) conduct of others need not and often does not involve an accompanying intent to avert harm. ${ }^{54}$ People and corporations often apply a proper or reasonably safe course of action as the product of mimicking the example of others engaged in similar activities, or of following custom or a market standard or the practices and experience of the past. There is no particular reason to think that intending to avert harm is involved where one is focused on implementing custom, market standards or the example of others. In such circumstances one may perform an action without any awareness of its safetyoriented nature. Another type of case is relying on a role model or on expert opinion or skill as a means of satisfying a duty of care to apply safety-oriented practices and decision-making processes. Here it is perhaps likely that the expert's actions are accompanied by intent to avert harm, yet the actor who hired the expert or is following the expert's lead need not have such an intention accompany his conduct when hiring the expert and in following her advice and still may successfully meet the safety-oriented standard of conduct of the duty of care. The same is often true for following policy, orders, rules and instructions. In learning from and in relying on the judgment and example of others, actors may, and I dare say often do, follow all the required safety-oriented practices and incorporate all the mandated safety considerations and risk calculations required by a duty of care without ever intending to avert harm. The possibility of satisfying a duty of care through mimicking, following advice or adhering to experience, custom, policy or orders weakens the view that the duty of care gives rise to a de facto duty to intend to avert harm.

The argumentative weight of such counterexamples derives from their pervasiveness. The more ubiquitous and available the option of compliance with duties of care through mimicking, etc. the less compelling the idea of a de facto duty to try becomes. It is my sense that in modern society we very often learn how to act and how to fulfill our duties to act with reasonable care without ever considering the harm we are likely averting in so acting. In such cases we mostly act with due care not serendipitously but because we follow the example, custom, experience and instructions of others. Moreover, mimicking, etc. are also often the more prudent and practically viable courses of action (from the standpoint of avoiding liability and averting harm), considering the complexity of modern life and the essential role division of labor plays in guiding and assisting people with making the right choices.

These are of course not conclusive or categorical arguments against the idea of a de facto duty to try in negligence but they certainly demonstrate that a duty to try is not a feature of all or even most manifestations of the duty of care. There are many cases wherein one is likely and at times advised to satisfy one's duty of care through means other than intending to avert harm. At most, the duty of care only occasionally gives rise to a de facto duty to try. Thus, even if in practice the

54. In fact, occasionally custom is adopted as the standard for reasonably risky conduct. See Harper, supra note 8 at 653-73. 
duty of care at times gives rise to a de facto duty to try, clearly a de facto duty to try is not a necessary or even a central feature of the reality of compliance with the duty of care.

\section{A Conduct-Based Account of the Duty of Care}

In the preceding sections I explored the proposition that the duty of care is a duty to try and rejected it as a descriptive account of positive law, a revisionary account of the form the legal duty of care should have and a factual account of a de facto duty to try. Therefore, while, as explained above, the idea of the duty of care as a duty to try is promising - offering a compelling account of the responsibilitycomponent in negligence, accounting for the fact that at times acting with care necessarily incorporates, as a practical matter, an intention to avert harm, as well as (seemingly) capturing the essence of 'care' in the 'duty of care' - the idea of a duty to try is incompatible with the negligence standard's duty of care.

Rather than comprising a conjunctive intent-/action-based duty, the better view of the nature of the duty of care is the prevailing one: the duty of care sets a standard of conduct alone. It is, in other words, a duty 'to do' or a 'duty to succeed,' and not a duty to try. A conduct-based account of the duty of care does not suffer from the difficulties that plague Gardner's intent-/action-based approach. First, it better corresponds to the core of legal negligence. Second, the conduct-based account only suggests - not mandates - 'trying' to avert harm when it is prudent to do so, i.e., where preventing negligent harm is best achieved by trying to avert harm. In such circumstances people may sensibly choose or intentionally become accustomed to trying to avoid harm when engaged in risky conduct. The conduct-based account of the duty of care is better tailored, therefore, to the goal of harm prevention. It is also less disruptive to autonomy and freedom of thought. Third, it does not generate the probative hurdles involved in proving a lack of intent.

The duty of care in negligence is, therefore, a duty for certain conductnamely for reasonable conduct - that does not incorporate an additional duty to have any specific type of mental state in so acting. In Gardner's terms, the duty of care is not a duty to try to avert harm but a duty to succeed in generating reasonable conduct.

\section{The Conditional Responsibility-Component in Negligence}

As was stipulated above, for negligence to involve responsibility the negligence standard must somehow relate to actors' agency, or more specifically to their capacity for responsibility. If responsibility had no such role in the negligence standard, negligence would be similar to strict liability, in which the grounds for legal liability do not correspond to any grounds for moral responsibility. Swallowing the bitter pill of accepting that injecting the duty of care with an intentional component (along the lines of Gardner's duty to try) is a non-starter reintroduces the question of where (if anywhere) in the standard of negligence the responsibility-component lies. 
I believe the answer is found in the conditions for the applicability of the negligence standard. The conditions for being subject to the negligence standard appear to mostly match up with the conditions for moral responsibility: namely that people are responsible if and only if they possess a capacity for rational action under conditions allowing for the exercise of that capacity. ${ }^{55}$ It seems, therefore, that possessing the capacity to intentionally or knowingly comply with the duty of care is a condition for being subject to the duty of care.

That responsibility-capacity plays a conditional role in the negligence standard becomes apparent when exploring doctrines excluding the applicability of the legal duty of care to people with limited capacities of reasoning and understanding. The most obvious example involves children. Minors are often immune from negligence liability because they are considered incapable of negligence. The laws governing minors' negligence liability differ from one jurisdiction to another, but in its full manifestation the rule minimizing children's exposure to negligence liability maintains that children below the age of seven (or, alternatively, six, five, four or three) lack the capacity for negligence while older children - up until age fourteen or even sixteen - are often presumed to lack that capacity. ${ }^{56}$ For older children the standard of conduct is mostly tailored to the particular child and based on a notion of a reasonable teenager of the same age, intelligence, and experience acting under the same circumstances as the actual potentially negligent teenager. ${ }^{57}$ In any case, most jurisdictions accept that there is a spectrum of responsibility-capacity spanning from infancy to adulthood and that the closer a child is to adulthood the greater the scope of her potential negligence liability becomes. ${ }^{58}$ This gradual growth in the degree of exposure to negligence liability corresponds to the fact that the capacities for understanding and reasoning, which comprise responsibility-capacity, normally develop gradually throughout childhood.

Voluntary intoxication is a second example. Negligence liability may apply to harm one caused when intoxicated if - when choosing to become intoxicated - it was reasonably foreseeable that one's intoxication would generate an unreasonable risk or unreasonable conduct. ${ }^{59}$ Because when intoxicated one's responsibility-capacity is impaired and even suspended, negligence can only arise from one's conduct prior to actual intoxication. ${ }^{60}$ It is not surprising, therefore, that one is not negligently liable for harms one caused when involuntarily intoxicated, ${ }^{61}$ a state in which one's responsibility-capacities are temporarily impaired or diminished due to no fault of one's own.

Thus, where an actor lacks the capacity to perform — as a rational agent - the conduct a duty of care mandates or where the circumstances are such that one does

55. Hart, supra note 1 at 154-55.

56. Dobbs, supra note 1 at 297-98; Harper, supra note 8 at 489-90; Restatement (Second) of the Law of Torts $\S 283 \mathrm{~A}$, cmt. a.

57. Restatement (Second) of the Law of Torts $\S 283$ A.

58. See, e.g., Harper, supra note 8 at 485-90.

59. Dobbs, supra note 1 at 291; Restatement (Second) Torts $\S 283$ C, cmt. d.

60. There are degrees of intoxication and corresponding degrees of how intoxication impairs the capacities for responsibility. For purposes of simplicity these nuances are not weaved into the analysis.

61. Restatement, supra note 59. 
not have the opportunity to exercise one's agency, one is (due to a lack of capacity) not responsible or at fault for failing to comply with a duty of care and should not, therefore, be held negligently liable. Agency and responsibility-capacity are therefore conditions for negligence liability; conditions that match up with the conditions of moral responsibility. In other words, trying is not a part of the duty of care but the capacity to try is a condition for the duty's applicability.

Clearly the conditions for negligence liability in the law may, on occasion, differ from the conditions for moral responsibility. Sometimes negligence liability is attached to those who lack the capacity to adhere — as rational agents - to a duty of care. In most cases of legal negligence the reasonably prudent person standard delineates the scope of the duty of care and is the metric for assessing the reasonableness of conduct. The range of people to whom this standard applies spans from people with superior cognitive and rational capacities to those whose ability to understand and reason is below average (including people with certain reduced mental capacities ${ }^{62}$ and even, in certain circumstances, children ${ }^{63}$ ).

While in first-order morality the negligence standard applies a standard of conduct that must take into account the degree of every individual's responsibilitycapacity, the law mostly employs an objective standard. In first-order morality, whether a person did or did not have the capacity for responsibility over a specific action or outcome is a function of that particular individual's cognitive and rational capacities. In the law, the operative issue is not whether the specific person possessed the capacity for responsibility but rather, as just explained, what a reasonably prudent person would have done, known and understood under the same circumstances. The legal standard is therefore tailored to the responsibility-capacity of the reasonable person and not of the actual actor. This mechanism may generate discrepancies between the applicability of legal and moral duties of care, such as in the case of people with relatively reduced mental capacities.

The law's objective standard should, however, mostly aspire to approximate the responsibility-capacity of most people, thereby corresponding to the moral standard of care, yet it need not always do so. My objection to the legal standard straying too far from most people's actual responsibility-capacities is not only the well-known moral objection - an ought assumes that those subject to it can abide by it - but also jurisprudential. The principle of the rule of law prescribes that people should be ruled by law and that the law should be such that it can guide people. ${ }^{64}$ To best realize the rule of law principle a legal system must be able to regulate conduct and guide behavior-its primary functions. ${ }^{65}$ One condition for achieving the rule of law is imposing

62. Restatement (Second) of the Law of Torts $\S \S 283$ B, 289, cmt. N.

63. Children engaged in dangerous adult activities, such as operating a car, boat, machine, snowmobile or plane, see Dellow v. Pearson, 259 Minn 452 (1961), or in inherently dangerous activities, see Restatement (Second) of the Law of Torts $\S 283 \mathrm{~A}$, are mostly held to the regular standard of the reasonable person and not to the special standard tailored for minors. The justifications for this practice are mostly based on policy considerations. Such considerations include protecting children from their own contributory negligence, encouraging child development and protecting children's future as adults. See Dobbs, supra note 1 at 295-97.

64. Joseph Raz, The Authority of Law (Oxford: Oxford University Press, 1979) at 213.

65. Raz, ibid. at 214; Andrei Marmor, "The Rule of Law and Its Limits" (2004) 23 Law \& Phil. 1 at 5. See also H.L.A. Hart, "Lon L. Fuller: The Morality of Law" in Essays on Jurisprudence and Philosophy (Oxford: Clarendon Press, 1983) 343 at 349-51. 
legal norms people have the capacity to adhere to. ${ }^{66}$ Setting the bar too high for too many people would render the law ineffective and cripple the rule of law.

The need for an objective standard in the law may and mostly does justify the marginal cases wherein a particular person may have lacked the capacity for responsibility and is still, nevertheless, held to a duty of care and to its reasonably prudent person standard. Too narrowly defining the group to which an objective standard of care applies runs the risk of greatly increasing the number of people requiring a specially tailored standard of conduct, which would render the legal standard inefficient as a tool of regulation and would adversely affect people's ability to rely on the law and to develop reliable expectations as to the conduct of others. After all, assessing the responsibility-capacity of others is a difficult task indeed. Moreover, requiring a specially tailored standard of care that fits the responsibility-capacities of each defendant would generate insurmountable evidentiary complexities in litigating and adjudicating negligence claims. Where the law holds those lacking responsibility-capacity to the negligence standard, the law parts ways with the responsibility-based grounds for negligence liability because in such cases legal negligence does not require responsibility as a condition for liability. ${ }^{67}$ When justified, these cases are usually the product of the law effecting a compromise between competing values. ${ }^{68}$

In any case, what is important for us here is not the exact nature of the justification for the law's occasional deviations from the responsibility-condition for negligence liability but more the fact that such a justification is called for. The law's default position seems to be that negligence liability and the applicability of the negligence standard are conditioned on the defendant (or, in the case of comparative negligence, the plaintiff) possessing sufficient responsibility-capacities. The core of legal negligence assumes responsibility-capacity. It is at the margins that negligence liability is imposable on those whose responsibility-capacities are underdeveloped, severely impaired, insufficient or suspended. At its core, the negligence standard only applies to subjects possessing sufficient responsibility-capacities, as does moral responsibility.

That the responsibility-component in the negligence standard is found in its conditions of applicability is nicely fleshed out when observing that under the strict liability standard no such conditions of applicability arise. This is not surprising considering that, unlike the negligence standard, the strict liability standard does not require fault and responsibility as conditions for imposing liability. Where the negligence and the strict liability standards differ therefore is not, as Gardner believes, in the form or the nature of the duties they comprise ${ }^{69}$ - both standards contain (in Gardner's terms) a duty to succeed and not a duty to try-but in the conditions for their applicability.

Legal examples of how the strict liability standard applies to subjects lacking responsibility-capacities are most likely only found in cases of temporary involuntary

66. Lon L. Fuller, The Morality of Law (New Haven CT: Yale University Press, 1969) at 70-81.

67. Hart, supra note 1 at 154-55.

68. Competing considerations include the expectations of others, difficulty in proving a subjective standard and maximizing overall social welfare. Hart, supra note 1 at 153 . See also Oliver Wendell Holmes, The Common Law (New York: Dover Publications, 1991) at Lecture III (emphasizing the problematic probative implications of adopting a subjective standard of conduct in negligence). 69. Assuming that strict liability indeed comprises a duty at all and is not merely a pure liability rule. 
impairment or suspension of such capacities. Non-agents are mostly not subject to legal duties and obligations, and considering that the days of suing animals are long gone, a subject of strict liability must be, in principle or by type, an agent.

One example of how strict liability can apply to subjects with suspended responsibility-capacities is the case of involuntary intoxication. A person who acts out of involuntary intoxication may be liable for his actions and their outcomes under strict liability, even if he could not have been — as a matter of capacity-responsible for his actions. See, e.g., State v. Hammond ${ }^{70}$ wherein the Supreme Court of New Jersey held that involuntary intoxication was not a valid defense to a drunk-driving charge. In contrast, as explained above, involuntary intoxication is a valid defense against negligence liability. The same contrast seems to arise in the case of children who are, at times, categorically or presumptively immune from negligence liability (or held to a relaxed standard of care) yet are not similarly immune from strict liability. ${ }^{71}$

Consider another example. A person in a coma wholly inherits a Limited Liability Company (LLC): his father's petting zoo business. The father not only owned the zoo but was also its sole manager and operator. The business continues to 'run itself' after the father's death: the animals roam and live off the open range, patrons pay with credit cards at the automated gate and an external accountant handles the finances. Because no one is in control of the corporation, which is in principle considered a legal person subject to legal obligations, it seems that the corporation's agency is suspended. One day a sheep wanders off the zoo's territory, climbs over the neighbor's fence and feasts on the neighbor's cabbage patch. It is of course established law that "a possessor of livestock intruding upon the land of another is subject to liability for the intrusion [and for harm that resulted from the intrusion] although he has exercised the utmost care to prevent them from intruding." ${ }^{.72}$ At the time the sheep wandered off the petting zoo there was no agent or organ with the required responsibility-capacities through whom agency, fault and responsibility could be imputed to the corporation; a fact that under the strict liability rule for trespass by livestock does not immunize the corporation from liability to compensate the neighbor. In contrast, it seems that a corporation temporarily devoid of any agency cannot be negligent. ${ }^{73}$

A comparison with intentional torts is also illuminating. While the negligence standard shares similar conditions of applicability with the standard for intentional torts - both requiring functioning responsibility-capacity as a condition of applicability - the two standards are of course not identical. The difference is found in the structure of the duties the two standards impose. While negligence imposes a positive duty for performing certain conduct, intentional torts mostly comprise a negative duty to refrain from coupling certain types of mental states with certain types of conduct. Put differently, the form or nature of the grounds for liability in negligence and in intentional torts differs.

70. 118 N.J. 306 at 315-16 (N.J. 1990) (A charge was based on a provision that forbade operating a vehicle while intoxicated and as such applied a strict liability standard that did not allow for a defense of involuntary intoxication).

71. Restatement (Second) of the Law of Torts $\S 895 \mathrm{I}$.

72. Ibid. $\S 504$.

73. Discounting for the possibility of derivative responsibility grounded in past corporate actions. 
The grounds for (moral) responsibility for breaching the negligence standard and for violating an intentional tort also differ. Responsibility for intentional tortious actions turns on the awareness or control the agent exercises over those actions: performing them intentionally, willfully or knowingly. In contrast, when breaching the duty of care in negligence one's responsibility for failing to act reasonably is explained by a supplementary non control-based theory of moral responsibility, such as those offered by Sher and Raz. Such theories account for how, in certain circumstances, responsibility arises where a moral/rational agent unintentionally or unknowingly fails to satisfy a standard of conduct.

Correspondingly, the form of the responsibility-component found in the negligence standard and in intentional torts differs. In the case of intentional torts, the responsibility-component- setting the grounds of (legal) liability so that they match the grounds of (moral) responsibility - is the restriction on certain intentions (when coupled with certain conduct). In contrast, the responsibility-component in the negligence standard is not found in its duty of care. The duty of care is a duty for conduct alone, neither negatively challenging agency - there is no restricted 'negligence mental state' - nor positively - there is no (nor should there be) a duty to try. Rather, the responsibility-component in the negligence standard has a conditional form.

Yet, are the "conditions of applicability" sufficient to function as a responsibilitycomponent for the negligence standard? Do they in fact set the grounds for (legal) liability in a way that matches-up with the grounds for (moral) responsibility? I think they do, presuming we adopt a theory of responsibility that accounts for responsibility for unintentional failures, malfunctions or shortcomings in one's responsibility capacities. ${ }^{74}$ The duty of care in negligence requires (similar to the 'duty' in strict liability) certain conduct $\phi$. The conditions of the applicability of the duty of care (similar to those of intentional torts) assure that the duty to $\phi$ applies only to those with the responsibility-capacity and rational agency allowing them to comply with the duty to $\phi$ as rational agents. If one who has such a capacity to comply negligently fails to comply, the reason for failing seems to be some (unintentional or unknown) limitation, failure or malfunction in the agent's agency or responsibility-capacities. From this flows both liability (due to breaching the duty of care by failing to $\phi$ ) and responsibility (due to a malfunction or shortcoming in one's responsibility-capacities causing the failure to $\phi$ ) for the negligent conduct.

There is, therefore, a responsibility component in negligence. Only it is not found in the duty of care, as is assumed in the idea of the duty to try, but in the conditions of applicability of the duty of care as a duty for conduct.

\section{Conclusion: Negligence Responsibility and the Nature of the Negligence Standard}

My goal was to maintain the postulate that negligence assumes responsibility while critiquing the account of the duty of care as a duty to try. As a product of this critique I concluded that although it offers a promising account of the responsibility-

74. Such as the theories of Sher and Raz discussed above. 
component in the standard of negligence, the idea of the duty of care as a duty to try is both descriptively and doctrinally wrong as well as prescriptively undesirable. I therefore endorsed a pure conduct-based account of the duty of care. This raised anew the question of where in the negligence standard lies the responsibility-component accounting for the fact that negligence assumes responsibility. In response, I suggested a condition-based approach to the responsibility-component in negligence: the duty of care in negligence only applies where the circumstances are such that those subject to the duty are in a position and have the capacity to comply - as agents - with the conduct-based duty. In other words, to be subject to the conduct-based duty of care in negligence one must possess the capacity and the actual opportunity to willfully comply with the duty. Thus, the conditions for being subject to the negligence standard (my proposed responsibility-component) mostly parallel the conditions for moral responsibility.

That the negligence standard requires the capacity to willfully, intentionally or knowingly comply with the duty of care as a condition for its applicability does not entail that the negligence standard mandates that when complying with the conduct requirements of the duty of care one actually intend to do so. The negligence standard makes no positive demands on one's agency (beyond what is required for performing the mandated conduct). One may satisfy the negligence standard's duty of care without exercising one's responsibility-capacities at all. The duty of care is a duty for conduct alone, and one need not be responsible for one's reasonable conduct in order to avoid negligence liability. However, one who acts unreasonably or without care breaches the duty of care only if she had an operational capacity and opportunity to comply — as a rational agent - with the duty of care, yet failed to do so.

The emerging structure of the negligence standard is a little peculiar: comprising a duty for reasonable conduct that does not mandate intending to avert harm, yet only applying where the actor's capacities and the background conditions allow for such intentional or willful compliance. Thus, while liability for negligent conduct may only arise where one could have intended to act safely or with the view of averting harm, such liability is never predicated on the failure to so intend but only on one's unreasonable conduct.

In summary, the responsibility-component in negligence does not take the form of a positive duty to intend to avert harm but rather of a condition to have the capacity and reasonable opportunity to intentionally or willfully comply with the conductbased duty of care. The duty of care in negligence only requires conductregardless of how one's agency and responsibility-capacities are engaged with the conduct - but only applies where one could have exercised one's agency and responsibility-capacities to bring about the required conduct. In Gardner's terms, the negligence standard's duty of care is a duty to succeed (or 'to do') that is conditioned on the capacity to try. 